\title{
Clear-cell papillary renal cell carcinoma: molecular and immunohistochemical analysis with emphasis on the von Hippel-Lindau gene and hypoxia-inducible factor pathway-related proteins
}

Stephen M Rohan ${ }^{1}$, Yonghong Xiao ${ }^{1}$, Yupu Liang ${ }^{2}$, Maria E Dudas ${ }^{1}$, Hikmat A Al-Ahmadie ${ }^{1}$, Samson W Fine ${ }^{1}$, Anuradha Gopalan ${ }^{1}$, Victor E Reuter ${ }^{1}$, Marc K Rosenblum ${ }^{1}$, Paul Russo ${ }^{3}$ and Satish K Tickoo ${ }^{1}$

${ }^{1}$ Department of Pathology, Memorial Sloan-Kettering Cancer Center, New York, NY, USA;

${ }^{2}$ Department of Computational Biology, Memorial Sloan-Kettering Cancer Center, New York, NY, USA and

${ }^{3}$ Department of Urology, Memorial Sloan-Kettering Cancer Center, New York, NY, USA

Over the past few years several investigators have independently described unique low-grade renal epithelial neoplasms with clear cytoplasm, focal to diffuse papillary architecture, and occasional leiomyomatous stromal metaplasia that are not currently recognized in the World Health Organization classification of renal tumors. These tumors have been referred to by a variety of names including clear-cell papillary renal cell carcinoma and recently "clear-cell tubulopapillary renal cell carcinoma". On the basis of the available data, such tumors are positive for cytokeratin 7 (CK7) and carbonic anhydrase IX (CA9), while being negative for CD10, $\alpha$-methylacyl-CoA racemase (AMACR), and TFE3. These tumors reportedly lack trisomies of chromosomes 7 and 17, deletions of 3p25, von Hippel-Lindau (VHL) gene mutations, and VHL promoter hypermethylation. Herein, we report on nine cases of this tumor emphasizing detailed studies of the VHL gene and hypoxiainducible factor (HIF) pathway. Molecular studies performed included VHL mutational analysis, copy number changes assessed using single-nucleotide polymorphism arrays, and qRT-PCR for VHL mRNA expression. Immunohistochemical stains for markers of HIF pathway activation (HIF-1 $\alpha$, CA9, and glucose transporter-1 (GLUT-1)) as well as other relevant markers (CK7, CD10, AMACR, and TFE3) were performed. None of our tumors harbored VHL gene mutations, losses of chromosomal region 3p25, or trisomies of chromosomes 7 or 17. VHL mRNA was overexpressed in our tumors relative to normal renal tissue and clear-cell renal cell carcinoma. All cases showed strong co-expression of CK7, HIF-1 $\alpha$, GLUT-1, and CA9. No expression of TFE3, CD10, or AMACR was seen. The morphological, immunophenotypic, and molecular features of these unique low-grade tumors are sufficiently distinct to allow separation from other renal cell carcinoma subtypes. The coexpression of CA9, HIF-1 $\alpha$, and GLUT-1 in the absence of VHL gene alterations in clear-cell papillary renal cell carcinoma suggests activation of the HIF pathway by non-VHL-dependent mechanisms.

Modern Pathology (2011) 24, 1207-1220; doi:10.1038/modpathol.2011.80; published online 20 May 2011

Keywords: clear-cell papillary renal cell carcinoma; hypoxia-inducible factor pathway; von Hippel-Lindau

Correspondence: Dr SM Rohan, MD, Department of Pathology and Laboratory Medicine, Northwestern Memorial Hospital, Northwestern University-Feinberg School of Medicine, Feinberg Pavilion 7-334, 251 Huron Street, Chicago, IL 60611, USA.

E-mail: s-rohan@northwestern.edu

Received 30 November 2010; revised 16 March 2011; accepted 17 March 2011; published online 20 May 2011
The current World Health Organization (WHO) classification of genitourinary tumors recognizes over 40 subtypes of renal neoplasms. ${ }^{1}$ Since the publication of the latest iteration of the WHO classification in 2004, several novel renal tumor subtypes have been described. One such subtype is clear-cell papillary renal cell carcinoma, a typically low-grade renal epithelial neoplasm with morpho- 
logical features mimicking both clear-cell renal cell carcinoma and papillary renal cell carcinoma that also occasionally exhibits prominent smooth muscle metaplasia within the intratumoral stroma. We, and others, believe that a variety of other recently described entities, including renal angiomyoadenomatous tumor, ${ }^{2}$ clear-cell tubulopapillary renal cell carcinoma ${ }^{3}$ renal cell carcinoma with prominent leiomyomatous proliferation ${ }^{4}$ and clearcell renal cell carcinoma with diffuse cytokeratin 7 immunoreactivity ${ }^{5}$ are either closely related, if not the same, tumors as clear-cell papillary renal cell carcinoma described in the literature with alternative nomenclature ${ }^{3,5-8}$ Our contention is further supported by presentations at the most recent annual meeting of United States and Canadian Association of Pathologists (USCAP, 2011) regarding clear-cell papillary renal cell carcinoma and renal angiomyoadenomatous tumor. ${ }^{9,10}$

Despite the different nomenclature used, the tumors described share many morphological features and consistently express cytokeratin 7 (CK7) and carbonic anhydrase IX (CA9) while lacking labeling for $\alpha$-methylacyl-CoA racemase (AMACR) and CD10. ${ }^{2-4,6,7}$ An association with end-stage renal disease was initially described for clear-cell papillary renal cell carcinoma (RCC), but many cases have now been documented outside of this setting. ${ }^{3,6,7,11}$ At the molecular level, no consistent changes have been detected in these tumors. However, based on a few studies these unique tumors do appear to lack the molecular changes characteristic of clear-cell RCC-von Hippel-Lindau gene mutations/chromosome 3p25 loses-and papillary RCCtrisomies of chromosomes 7 and 17 with losses of chromosome $\mathrm{Y}^{3,6}$

In a recent series, 36 low-grade renal epithelial tumors with the characteristics outlined above were described in detail. ${ }^{3}$ Many additional cases were also reported at the most recent annual meeting of the USCAP (2011), confirming the unique immunophenotype of these and related tumors., ${ }^{9,10,12,13}$

The characteristic immunophenotype of these tumors includes diffuse CK7 expression in 100\% of cases, diffuse membranous CA9 expression, negative immunostaining for AMACR and TFE3, and negative or at the most focal expression of CD10. Many of these studies also confirm the absence of 3p25 losses and trisomies of chromosomes 7 and 17 in these tumors. Aydin et $a .^{3}{ }^{3}$ also found no VHL promoter hypermethylations in two cases they tested. On the basis of such results, it appears that these tumors represent a distinct form of low-grade RCC, the recognition of which may be important for prognosis and clinical management. ${ }^{3,7}$

The emphasis placed on the VHL gene in these previous studies is warranted based on the morphological overlap between clear-cell RCC and clear-cell papillary RCC, as well as the fact that much of the molecular genetic underpinnings of the modern classification of renal tumors has been elucidated through the study of inherited cancer syndromes such as VHL disease. ${ }^{1,14}$ Over the years, numerous studies have documented somatic mutations and promoter hypermethylation of the VHL gene as well as losses of chromosome $3 p$ in sporadic clear-cell RCC, and such alterations have become defining characteristics of these tumors. ${ }^{1,15-17}$ The VHL gene product regulates transcription of several genes through the hypoxia-inducible factor (HIF) pathway. ${ }^{18}$ Silencing of VHL expression ultimately results in overexpression of a number of proteins, including HIF-1 $\alpha$, glucose transporter-1 (GLUT-1), and CA9. ${ }^{19-21}$

We evaluated the morphological, immunohistochemical, and molecular features of nine cases of clear-cell papillary RCC with emphasis on the VHL gene and HIF pathway-related markers, given the importance of this gene and pathway in clear-cell RCC-the main differential diagnostic consideration. Mutational analysis of the entire VHL gene was performed in each case to exclude such mutations as a possible mechanism of gene silencing. In addition, chromosomal copy number changes were evaluated in clear-cell papillary RCC using single-nucleotide polymorphism (SNP) arrays to examine genomewide changes and exclude the presence of recurrent copy number changes-such as losses of $3 p$ and/or $5 \mathrm{q}$ gains-that are known to occur in clear-cell RCC. ${ }^{16,22-24}$ Quantitative real-time PCR (qRT-PCR) was carried out to evaluate VHL mRNA expression in clear-cell papillary RCC. Finally, we performed immunohistochemistry for markers of HIF pathway activation (CA9, HIF- $1 \alpha$, and GLUT-1) and additional markers (CK7, AMACR, TFE3, CD10, and $34 \beta \mathrm{E} 12)$ shown to be relevant in the diagnosis/ differential diagnosis of these tumors.

\section{Materials and methods}

\section{Selection of Samples}

The Memorial Sloan-Kettering Cancer Center institutional review board approved this study. A total of nine clear-cell papillary RCC cases with available frozen tumor and normal kidney samples which had undergone resection at our institution between 2005 and 2008 were identified in our files. These nine cases-along with 11 clear-cell RCC and 13 papillary RCC-were selected for inclusion in this study. Clinical history and family history were obtained by chart review. All available H\&E slides from each case were reviewed by two genitourinary pathologists (SKT, SMR). Recognition and classification of a tumor as clear-cell papillary RCC was based on the findings of previous studies. ${ }^{6,7,8,11}$ Specifically, the criteria used for classification of a tumor as a clearcell papillary RCC included the following: (1) diffuse cytoplasmic clarity; (2) variable, often conspicuous, papillary architecture; and (3) characteristic linear arrangement of the nuclei away from the basement membrane (Figure 1). After review of all the slides from a given case, a single tumor-containing 

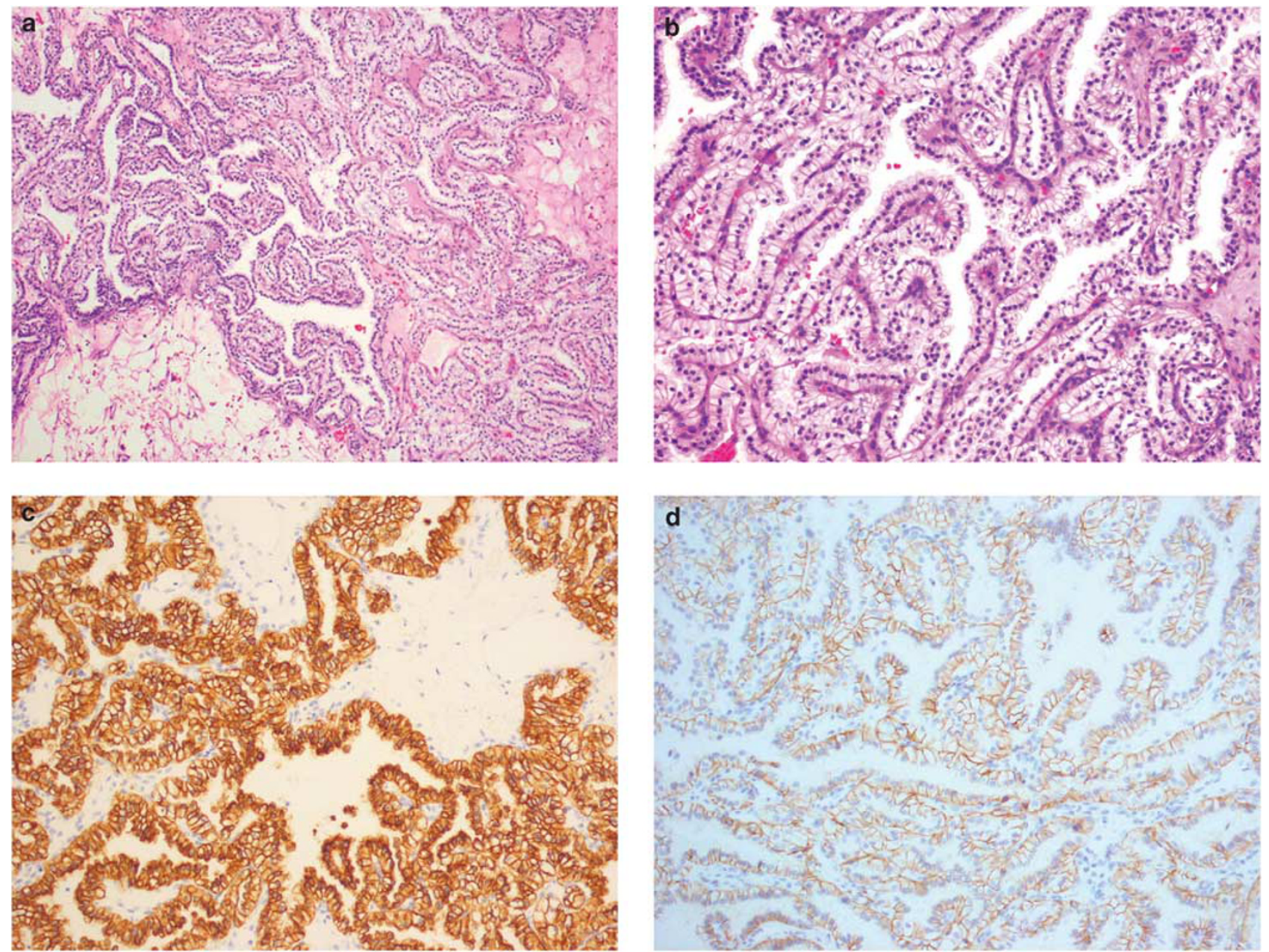

Figure 1 An example of a clear-cell papillary renal cell carcinoma is depicted in the photomicrograps. This example has diffusely papillary architecture and conspicuous cytoplasmic clarity $(\mathbf{a}, \mathrm{H} \& \mathrm{E}, \times 100)$. Higher-power examination reveals positioning of the nuclei away from the basement membrane toward the luminal aspect of the cell. This morphological feature was consistently seen in all clear-cell papillary carcinomas in this study $(\mathbf{b}, \mathrm{H} \& \mathrm{E}, \times 200)$. Diffuse, strong membranous co-expression of CK7 (c, $\times 200)$ and CA9 (d, $\times 200)$ is characteristic of these tumors. Note the absence of luminal staining for CA9, which is characteristic of clear-cell papillary renal cell carcinoma.

Table 1 Antibodies

\begin{tabular}{llcl}
\hline Antibody & Company/source & Dilution & Antigen retrieval method \\
\hline CK7 & Ventana & Pre-diluted & Proteinase K \\
AMACR & DAKO & $1: 500$ & Citric acid \\
CA9 & Proprietary (clone M75/38) & $1: 250$ & Citric acid \\
TFE3 & Santa Cruz Biotechnology & $1: 500$ & EDTA \\
$34 \beta$ E12 & Ventana & Pre-diluted & Proteinase K \\
CD10 & Novocastra & $1: 300$ & Citric acid \\
HIF-1 $\alpha$ & NOVUS Biologicals & $1: 400$ & Catalyzed signal amplification system (DAKO) \\
GLUT-1 & Cell Signaling Technology & $1: 500$ & Citric acid \\
\hline
\end{tabular}

paraffin block was chosen and a tissue microarray (TMA) was constructed. Each case was represented on the TMA by three, 2.0-mm tissue cores.

\section{Immunohistochemistry}

Immunohistochemistry was performed on TMA slides containing all cases and repeated on whole sections in selected cases with the antibodies listed in Table 1. Antigen retrieval was performed as listed in Table 1. Visualization of bound antibodies was performed using the peroxidase-labeled streptavidin-biotin system (DAKO, LSAB2 kit) with 3, 3diaminobenzidine as a chromagen. Positive and negative controls were run concurrently and showed appropriate immunostaining. Immunohistochemical staining was graded in a semiquantitative manner as absent/weak ( 0 or $1+, 0-25 \%$ cells positive) or strong $(2+$ or $3+, 26-100 \%)$. Cytoplasmic and/or 
Table 2 Sequencing primers

\begin{tabular}{|c|c|c|}
\hline Gene & Target position & Primer sequence (with M13 tails; $5^{\prime}-3^{\prime}$ ) \\
\hline$V H L$ & chr3:10158318-10158698 & GTAAAACGACGGCCAGTaaccttagaggggcgaаaаa \\
\hline$V H L$ & chr3:10158318-10158698 & CAGGAAACAGCTATGACCgcttcagaccgtgctatcgt \\
\hline$V H L$ & chr3:10158699-10158871 & GTAAAACGACGGCCAGTTAACGAGTTGGCCTAGCCTC \\
\hline VHL & chr3:10158699-10158871 & CAGGAAACAGCTATGACCGCTTCAGACCGTGCTATCGT \\
\hline VHL & chr3:10163197-10163320 & GTAAAACGACGGCCAGTggacggtcttgatctcctga \\
\hline$V H L$ & chr3:10163197-10163320 & CAGGAAACAGCTATGACCcataacgtacaaatacatcacttcca \\
\hline VHL & chr3:10166470-10166850 & GTAAAACGACGGCCAGTGCAAAGCCTCTTGTTCGTTC \\
\hline VHL & chr3:10166470-10166850 & CAGGAAACAGCTATGACCAACGATATGCTGCAATTCCC \\
\hline$V H L$ & chr3:10166851-10167230 & GTAAAACGACGGCCAGTACAGGACTGGTTCCTTCCTT \\
\hline VHL & chr3:10166851-10167230 & CAGGAAACAGCTATGACCGACCGAGAAAGTGCACGACT \\
\hline$V H L$ & chr3:10167231-10167610 & GTAAAACGACGGCCAGTGAGCCTTCAGTCAGGGTTTG \\
\hline$V H L$ & chr3:10167231-10167610 & CAGGAAACAGCTATGACCGTACAAAAATTGGCCAGCGT \\
\hline VHL & chr3:10167611-10167990 & GTAAAACGACGGCCAGTCATCCGCACAGAAAATACGA \\
\hline$V H L$ & chr3:10167611-10167990 & CAGGAAACAGCTATGACCTCCAAATGTTTCTCTACTGGGG \\
\hline$V H L$ & chr3:10167991-10168370 & GTAAAACGACGGCCAGTTTTTATCAGGCAGGACCAGG \\
\hline VHL & chr3:10167991-10168370 & CAGGAAACAGCTATGACCCCAGCCGTCACTCTCATTTT \\
\hline VHL & chr3:10168371-10168746 & GTAAAACGACGGCCAGTCCACTTTTGTTCTACTCСTTCCС \\
\hline$V H L$ & chr3:10168371-10168746 & CAGGAAACAGCTATGACCGCTAAAATCAGTTGAAATTCGGA \\
\hline
\end{tabular}

membranous expression of CK7, CD10, and AMACR were considered positive. Only distinct membranous staining for CA9 and GLUT-1 and distinct nuclear staining for TFE3 were considered positive.

\section{DNA Extraction, VHL Sequencing, and Mutational Analysis}

Prior to DNA extraction, frozen section H\&E-stained slides from each aliquot of tumor and normal were prepared and examined to ensure that only tumor and normal were present, respectively. Genomic DNA was extracted from two $10-\mu \mathrm{m}$ frozen slices using the Genfind kit (Agencourt, Beverly, MA, USA), in a 96-well format, following the manufacturer's instructions, in a semiautomated manner as described previously. ${ }^{25}$ The average yield was $2 \mu \mathrm{g}$ of dsDNA. A total of $100 \mathrm{ng}$ of DNA were used for whole genome amplification using the Repli-G Midi kit (Qiagen, Valencia, CA, USA). The quality of whole genome amplified DNA was verified by PCR reactions using two control amplicons. The exonic regions of interest (NCBI Human Genome Build 36.1) were broken into amplicons of $500 \mathrm{bp}$ or less, and specific primers were designed using Primer 3, to cover the exonic region plus at least $50 \mathrm{bp}$ of intronic sequences on both sides of intron-exon junctions $^{26}$ (Table 2). M13 tails were added to facilitate Sanger sequencing. PCR reactions were carried out in 384-well plates, in a Duncan DT-24 water bath thermal cycler, with $10 \mathrm{ng}$ of whole genome amplified DNA (Repli-G Midi; Qiagen) as template, using a touchdown PCR protocol with HotStart Taq (Kapa Biosystems, Cape Town, South Africa). Mutations were detected using an automated detection pipeline at the MSKCC Bioinformatics Core as described previously. ${ }^{25}$ All putative mutations were confirmed by a second PCR and sequencing reaction, in parallel with amplification and sequencing of matched normal tissue DNA.

\section{SNP Array and Data Analysis}

The Affymetrix SNP 6.0 array contains more than 906600 SNP probes and 946000 copy number variation (CNV) probes. This array provides a complete genome-wide picture of CNV within a given sample. A total of $500 \mathrm{ng}$ of whole genomeamplified DNA was used for tumor and matched normal samples for SNP genotyping. The samples were fragmented and labeled according to the Affymetrix SNP Nsp/Sty 6.0 protocol for whole genome amplified DNA (Affymetrix, Santa Clara, CA, USA). The samples were then hybridized on the Affymetrix SNP 6.0 arrays for $18 \mathrm{~h}$ at $50^{\circ} \mathrm{C}$ in a GeneChip 450 hybridization oven (Affymetrix) at 60 r.p.m. The arrays were washed and stained according to the manufacturer's protocol. After scanning, quality control measures evaluated for each sample included the signal contrast QC and the SNP call rates. All samples had contrast QC $>1.3$ and SNP call rates $>93 \%$. The data were processed from the original CEL files with the Affymetrix Chromosomal Copy Number Analysis Tool (CNAT 4.0). The data were then analyzed using two independent methods. First, CEL files were imported into Partek Genomic Suite and analyzed using the Copy Number Analysis workflow with normalization performed using the robust multichip averaging (RMA) algorithm, and segmentation carried out using a hidden Markov model set to detect copy number states of $0.1,1,3,4$, and 5 as described previously. ${ }^{27}$ A copy number state of 2 was ignored and both SNP and CNV probes were used in the analysis. In a separate analysis of the same data set probe level signal intensity normalization (quantile) and copy number quantification of paired tumor and normal samples was generated using methods described previously. ${ }^{28}$ Raw copy number was obtained through a tumor-to-normal $\log _{2}$ ratio by subtracting the signal intensity of the matched normal sample from the tumor signal. Segmentation 
from the raw copy number data was performed using the circular binary segmentation algorithm. ${ }^{29}$ Each profile was centered so that $\log _{2}$ ratio of zero is assigned to the predominant copy number, determined by the mode of the distribution of the mean $\log _{2}$ ratio for each segment, weighted by the number of probes per segment. After mode-centering, gains and losses for a subset of analyses were defined as segment mean $\log _{2}$ ratios of $>0.2$ or $<-0.2$ and amplification and deletions as $>1$ or $<-1$, respectively. Copy number and $\mathrm{LOH}$ calls were made using the Rae algorithm. ${ }^{30}$ The results of the two analyses were compared and only changes consistently detected by each method were considered valid. Hierarchical clustering was performed using the median of $\log _{2}$ ratios for all SNPs in a chromosomal arm utilizing Pearson's centered distances with centroid linkage rule.

\section{RNA Extraction and VHL mRNA Expression by qRT-PCR}

Extraction of total RNA was performed using freshfrozen tissue from nine clear-cell papillary RCC cases, five clear-cell RCC cases with previously documented 3p25 losses and/or VHL gene mutations, and three non-neoplastic kidney tissue samples. Before extraction, frozen section H\&E-stained slides from each aliquot of tumor and normal were prepared and examined to ensure that only tumor and normal, respectively, were present. Total RNA was isolated homogenizing $1 \mathrm{mg}$ of tissue in $1 \mathrm{ml}$ of Trizol Reagent (Invitrogen, Carlsbad, CA, USA). The concentration and purity of the extracted RNA was determined using an Agilent 2100 Bioanalyzer. In all, $400 \mathrm{ng}$ of total RNA was reversetranscribed using the Thermoscript RT-PCR system (Invitrogen) at $52^{\circ} \mathrm{C}$ for $1 \mathrm{~h}$. A total of $20 \mathrm{ng}$ of resultant cDNA was used in a q-PCR reaction using the Applied Biosystems 7500 real-time PCR system and pre-designed TaqMan Gene Expression Assays Amplification was carried for 40 cycles $\left(95^{\circ} \mathrm{C}\right.$ for $15 \mathrm{~s}, 60^{\circ} \mathrm{C}$ for $\left.1 \mathrm{~min}\right)$. The $V H L$ forward primers (5'-CTGCCCGTATGGCTCAACTT-3') and reverse primers (5'-GTGTGTCCCTGCATCTCTGAAG-3') were obtained from Applied Biosystems (Foster City, CA, USA). To calculate the efficiency of the PCR reaction and to assess the sensitivity of each assay, we also performed a seven-point standard curve (5, 1.7, 0.56, 0.19, 0.062, 0.021, and $0.0069 \mathrm{ng})$. Triplicate Ct values were averaged for each sample, and amounts of target were interpolated from the standard curves and normalized to GAPDH.

\section{Statistical Analysis}

The $\chi^{2}$ contingency test was used to compare differences in copy number changes between tumor types. The Student's $t$-test was used to compare differences in $V H L$ mRNA expression between clear-
Table 3 Clinicopathological findings

\begin{tabular}{lcccccc}
\hline Case no. & Age (years) & Sex & Grade $^{\mathrm{a}}$ & Size (cm) & Stage & ESRD \\
\hline CCP1 & 60 & $\mathrm{M}$ & 2 & 2.2 & pT1a & No \\
CCP2 & 52 & $\mathrm{M}$ & 2 & 2.6 & pT1a & No \\
CCP3 & 56 & $\mathrm{M}$ & 2 & 2.1 & pT1a & No \\
CCP4 & 52 & $\mathrm{M}$ & 2 & 2.9 & pT1a & No \\
CCP5 & 74 & $\mathrm{~F}$ & 3 & 1.5 & pT1a & Yes \\
CCP6 & 73 & $\mathrm{M}$ & 2 & 3.1 & pT1a & No \\
CCP7 & 66 & $\mathrm{~F}$ & 2 & 2.3 & pT1a & No \\
CCP8 & 74 & $\mathrm{~F}$ & 2 & 2.1 & pT1a & No \\
CCP9 & 46 & $\mathrm{~F}$ & 3 & 2.8 & pT1a & No \\
\end{tabular}

ESRD, end stage renal disease.

${ }^{\mathrm{a}}$ Furhman nuclear grade.

cell papillary RCC, clear-cell RCC, and non-neoplastic kidney controls. Only $P$-values $<0.05$ were considered significant.

\section{Results}

\section{Clinicopathological Features}

The clinicopathological features of clear-cell papillary RCC cases included in this study are listed in Table 3. The patients consisted of five men and four women with a mean age of 61.7 years (range 46-74 years). One patient (CCP7) had multifocal, bilateral renal tumors, three of which were removed at our institution over a period of 6 years. Only one tumor from this patient, a $3.1 \mathrm{~cm}$ tumor removed in 2008, was used in this study. Of note, the two tumors removed form this patient before 2008 were both originally classified as clear-cell RCC, but on review all three tumors met the morphological criteria for clear-cell papillary RCC. This particular patient (CCP7) is also the only patient in our series with a family history of RCC, with her father having had bilateral nephrectomies for renal tumors. Clinical suspicion for VHL disease was high in this patient; however, she lacked any other stigmata of that syndrome and no other family members had any signs of VHL disease. Two other patients without family history of renal tumors had other lesions in addition to clear-cell papillary RCC including two papillary adenomas (CCP5) and a small angiomyolipoma (CCP8). The majority 8/9 (88\%) of patients with clear-cell papillary RCC underwent partial nephrectomy for their tumor(s). All patients were alive without evidence of disease at last follow-up. The mean tumor size was $2.4 \mathrm{~cm}$ (range $1.5-3.1 \mathrm{~cm}$ ) and all of the tumors were stage pT1a. None of the tumors had foci of lymphovascular invasion. Seven of nine $(78 \%)$ clear-cell papillary RCCs were Fuhrman nuclear grade 2, whereas the remaining two cases were Fuhrman nuclear grade 3 . All of the tumors had mixed growth patterns with variable amounts of papillary, tubular, and cystic architecture. The most common growth pattern was tubular, with $67 \%(6 / 9)$ of cases exhibiting this as the predominant architectural pattern. Two of the 

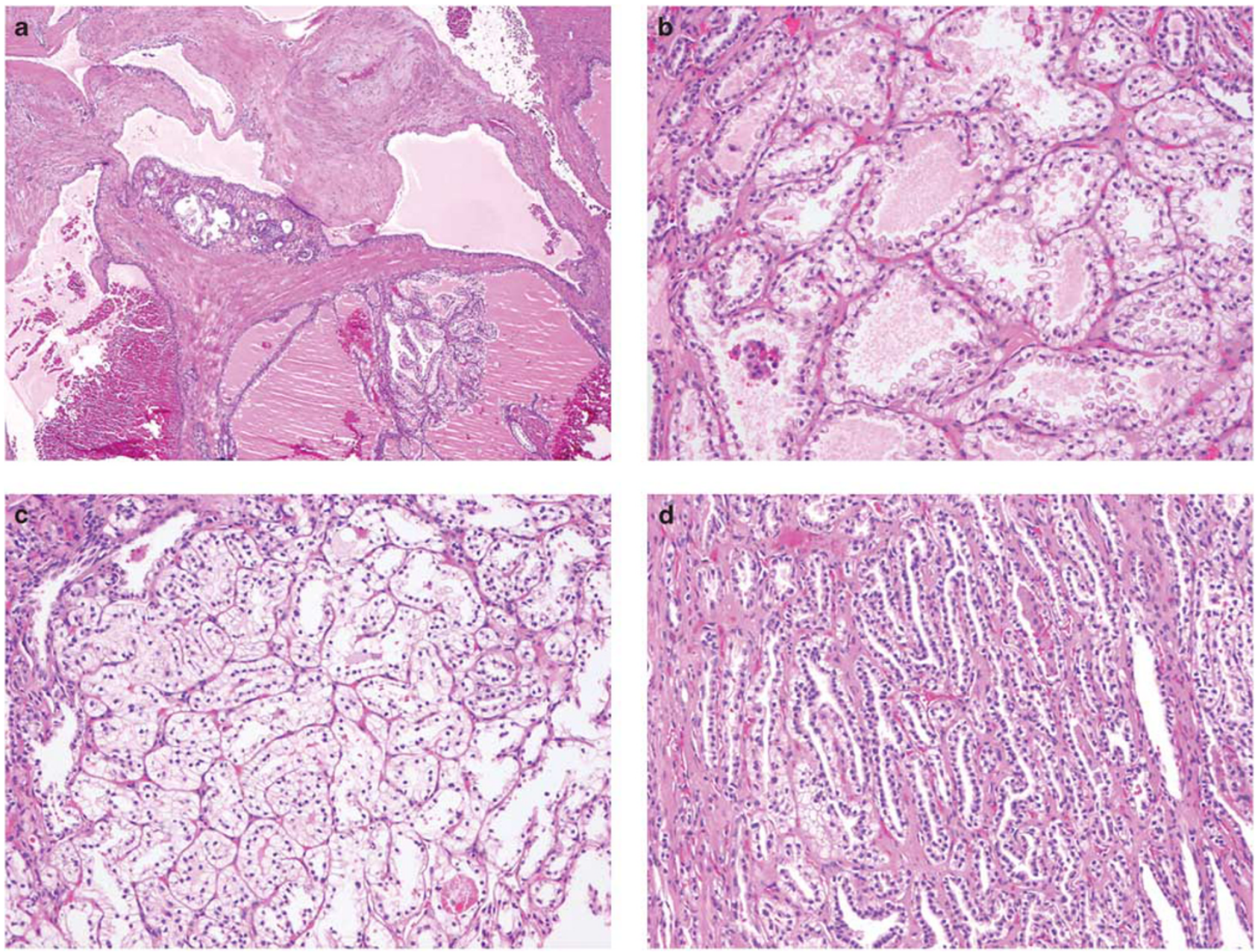

Figure 2 Papillary architecture is usually seen at least focally in clear-cell papillary renal cell carcinoma. However, many different architectural patterns can be seen, including prominent smooth muscle metaplasia $(\mathbf{a}, \times 100)$, tubular growth $(\mathbf{b}, \times 200)$, acinar growth $(\mathbf{c}, \times 200)$, and even a retiform-like pattern $(\mathbf{d}, \times 200)$. Diffuse cytoplasmic clarity and the characteristic nuclear positioning within the cytoplasm aid in proper identification of these tumors on H\&E-stained slides.

Table 4 Results of immunohistochemical staining in clear-cell papillary renal cell carcinoma

\begin{tabular}{|c|c|c|c|c|c|c|}
\hline Case no. & CK7 & CA9 & $34 \beta E 12$ & AMACR (\%) & CD10 (\%) & TFE3 (\%) \\
\hline CCP1 & $90 \%, 3+$ & $90 \%, 3+$ & $0 \%$ & 0 & 0 & 0 \\
\hline CCP2 & $90 \%, 3+$ & $70 \%, 3+$ & $80 \%, 3+$ & 0 & 0 & 0 \\
\hline CCP3 & $95 \%, 3+$ & $50 \%, 3+$ & $20 \%, 1+$ & 0 & 0 & 0 \\
\hline CCP4 & $95 \%, 3+$ & $50 \%, 3+$ & $20 \%, 1+$ & 0 & 0 & 0 \\
\hline CCP5 & $95 \%, 3+$ & $50 \%, 3+$ & $0 \%$ & 0 & 0 & 0 \\
\hline ССР6 & $90 \%, 2+$ & $90 \%, 3+$ & $50 \%, 2+$ & 0 & 0 & 0 \\
\hline CCP7 & $90 \%, 3+$ & $80 \%, 3+$ & $90 \%, 3+$ & 0 & 0 & 0 \\
\hline CCP8 & $95 \%, 3+$ & $80 \%, 3+$ & $90 \%, 3+$ & 0 & 0 & 0 \\
\hline CCP9 & $95 \%, 3+$ & $90 \%, 3+$ & $70 \%, 3+$ & 0 & 0 & 0 \\
\hline
\end{tabular}

tumors (CCP1 and CCP9) were predominately cystic and all of the tumors had areas of stromal sclerosis. In one case (CCP9), small areas of acinar-type growth were evident. In these acinar areas, the tumor cells tended to have larger amounts of clear cytoplasm, but the characteristic positioning of the nuclei away from the basement membrane/supporting vasculature was maintained (Figure 2). Four of the tumors (CCP3, CCP4, CCP5, and CCP6) had prominent smooth muscle metaplasia.

\section{Immunohistochemistry}

The results of CK7, CA9, 34 $\beta \mathrm{E} 12$, AMACR, CD10, and TFE3 immunohistochemical staining in clear- 


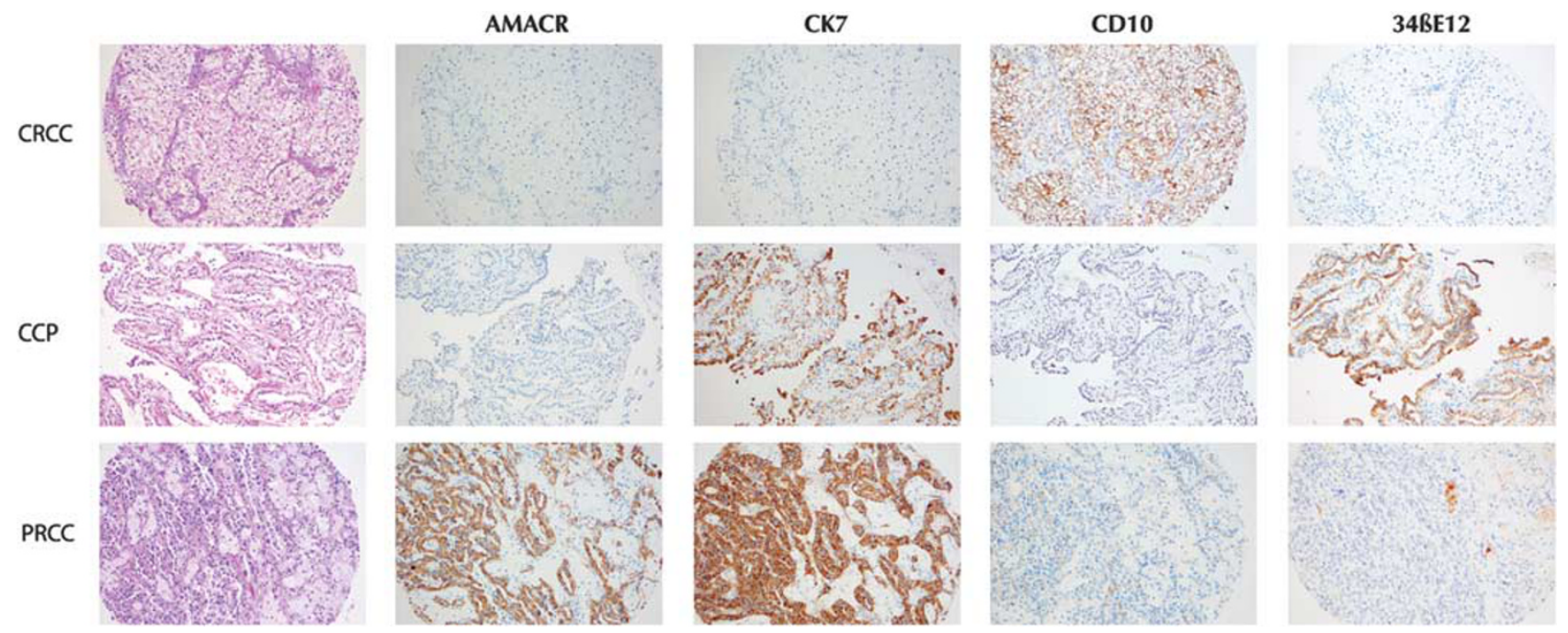

Figure 3 Immunohistochemistry can be helpful in distinguishing clear-cell papillary renal cell carcinoma (CCP) from clear-cell renal cell carcinoma (CRCC, top row) and papillary renal cell carcinoma (PRCC, bottom row). Note that many clear-cell papillary carcinomas label with 34BE12, while papillary renal cell carcinoma and clear-cell renal cell carcinoma were consistently negative for this marker.
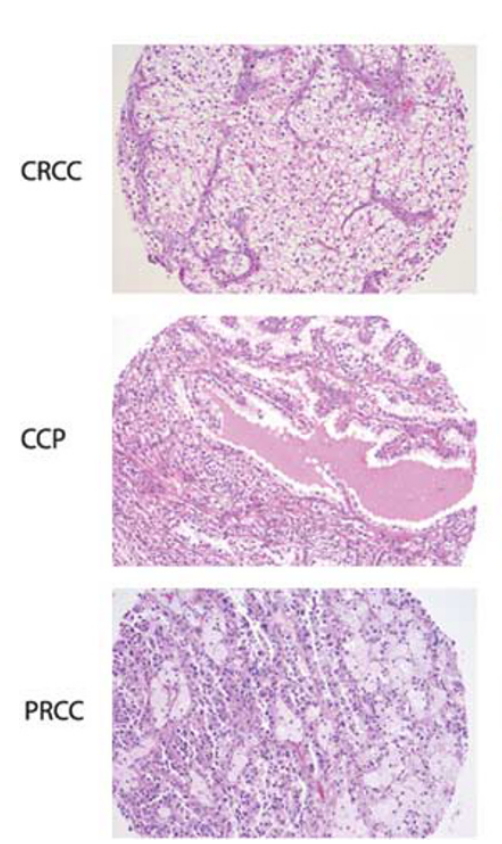
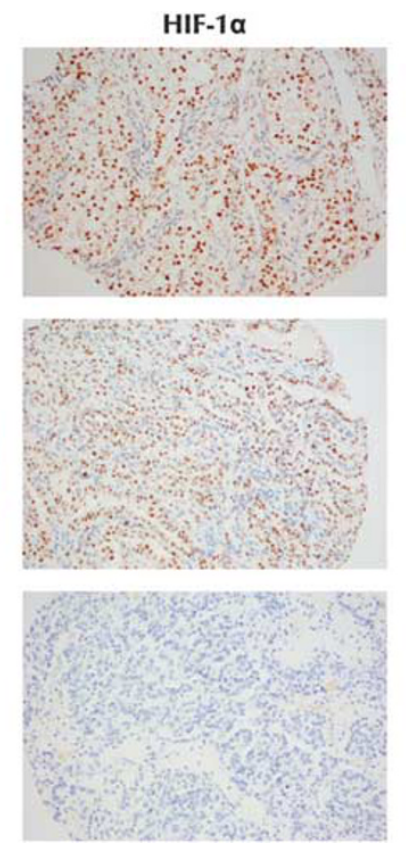
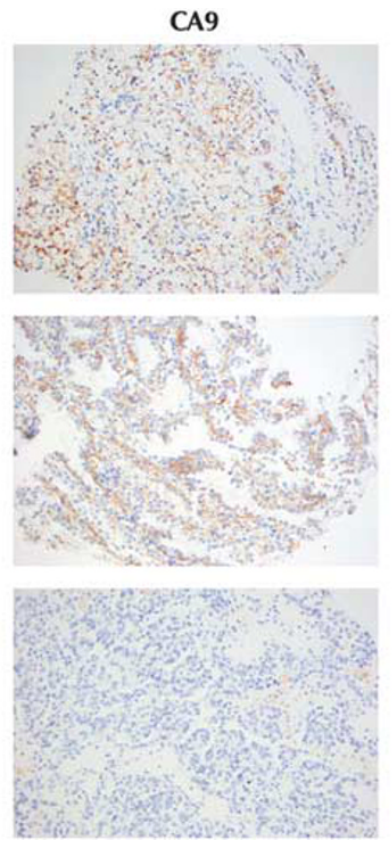
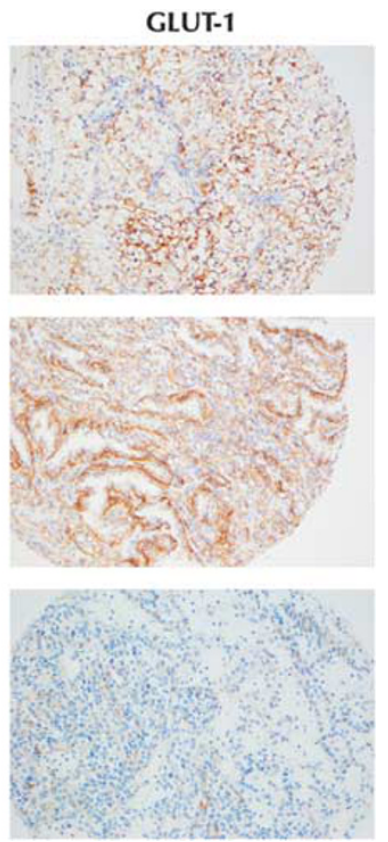

Figure 4 Immunohistochemical markers of HIF pathway activation (CA9, GLUT-1, HIF1 $\alpha$ ) label both clear-cell papillary (CCP) and clear-cell renal cell carcinoma (CRCC), while papillary renal cell carcinoma (PRCC) does not label with these markers.

cell papillary RCC are summarized in Table 4. All nine of the clear-cell papillary RCCs showed strong co-expression of CK7 and CA9 on the TMA slides. Whole sections of tumor were also stained with these two markers in six cases, all six cases exhibiting strong and diffuse co-expression of CK7 and CA9. The CA9 expression in clear-cell papillary RCC differed from that seen in clear-cell RCC in that there was generally an absence of staining at the luminal aspect of individual cells. This pattern of staining was not seen in any of our clear-cell RCC cases. In one clear-cell RCC case patchy staining for CK7 in addition to diffuse staining for CA9 was noted on whole sections. The CK7 staining in this case was centered around cystic spaces. Immunohistochemical staining for $34 \beta \mathrm{E} 12$ revealed strong, diffuse membranous labeling in 5/9 (56\%) clear-cell papillary RCCs, whereas none of the cases labeled with CD10 or AMACR. In contrast, clear-cell RCC labeled strongly with CA9 $(11 / 11,100 \%)$ and CD10 $(9 / 11,81 \%)$, but only rarely was strong expression of CK7 $(1 / 11,9 \%)$ seen in these cases. Labeling for $34 \beta$ E12 was not seen in clear-cell RCC $(0 / 11,0 \%)$. The papillary RCC immunoprofile also differed from that seen in clear-cell papillary RCC, with most cases being strongly positive for AMACR (11/13, 
Table 5 VHL mutational analysis results

\begin{tabular}{|c|c|c|c|c|c|c|}
\hline Sample & Tumor type & Exon & Mutation & Mutation type & Mutated protein & Mutation origin \\
\hline CRCC-3 & CRCC & 1 & c. $240 \mathrm{~T}>\mathrm{A}$ & Missense & S80R & Somatic \\
\hline CRCC-3 & CRCC & 1 & c. $241 \mathrm{C}>\mathrm{A}$ & Missense & P81T & Somatic \\
\hline CRCC-7 & CRCC & 1 & c. $234 \mathrm{~T}>\mathrm{A}$ & Missense & N78Y & Somatic \\
\hline CRCC-10 & CRCC & 1 & c.206_208delGCG & Nonsense & $\mathrm{E} 70^{\mathrm{a}}$ & Somatic \\
\hline
\end{tabular}

${ }^{\mathrm{a}}$ No mutations detected in CCP $(n=9)$ or PRCC $(n=13)$.

$85 \%)$ and CK7 (9/13, 69\%), but negative for CA9 (0/ $13,0 \%)$ and $34 \beta$ E12 $(0 / 13,0 \%)$ (Figure 3$)$. In addition to CA9, we evaluated immunoexpression of two other markers of HIF pathway activation, HIF- $1 \alpha$ and GLUT-1. The majority of clear-cell papillary RCCs expressed both of these markers, with $8 / 9(89 \%)$ cases exhibiting strong labeling for GLUT-1 and 9/9 (100\%) cases showing strong staining with HIF- $1 \alpha$ in a nuclear distribution. The findings in clear-cell RCC were similar, with 11/11 $(100 \%)$ cases strongly expressing GLUT-1 and 10/11 (91\%) cases strongly labeling with HIF-1 $\alpha$. These findings contrast with results seen in papillary RCC, none of which exhibited labeling for GLUT-1 or HIF-1 $\alpha$ (Figure 4). TFE3 nuclear labeling was not seen in any tumor.

\section{VHL Sequencing and Mutational Analysis}

The entire VHL gene was sequenced in 9 clear-cell papillary, 11 clear-cell, and 13 papillary RCCs along with matched non-neoplastic renal parenchyma samples. None of the clear-cell papillary or papillary RCCs exhibited VHL mutations. In all, 3 of the 10 clear-cell RCCs harbored VHL mutations (Table 5). All of these mutations were somatic and are predicted to result in either an amino-acid change or a premature stop codon. One case contained two mutations, a phenomenon that has been reported previously. ${ }^{17}$

\section{Chromosome Copy Number and Loss of Heterozygosity}

A total of 20 tumor and matched normal samples from 9 clear-cell papillary and 11 clear-cell RCC cases were evaluated for copy number changes and LOH using SNP arrays. Figure 5 shows unsupervised clustering of clear-cell papillary and clear-cell RCCs based on chromosomal copy number changes. Of note, this type of analysis does not result in distinct separate clustering of clear-cell papillary and clear-cell RCC. However, significant and potentially biologically relevant differences do exist. Table 6 lists the chromosomal copy number changes that differed significantly between clear-cell papillary RCC and clear-cell RCC. Most notably, only cases of clear-cell RCC $(7 / 11,64 \%)$ exhibited $3 p$ losses, whereas none of the clear-cell papillary RCC cases $(0 / 9)$ evaluated showed this change $(P=0.006)$ (Figure 6a). Additional copy number changes that were more frequently seen in clear-cell vs clear-cell papillary RCC and that are statistically significant include gains of $5 \mathrm{q}(P=0.025)$ (Figure $6 \mathrm{~b})$ and losses of $8 p(P=0.010)$. None of the clear-cell papillary RCC cases exhibited trisomies or tetrasomies of chromosomes 7 or 17. This finding was confirmed in all our clear-cell papillary RCCs by interphase fluorescence in situ hybridization using centromeric probes for chromosomes 7 and 17 (data not shown). No recurrent/type-specific chromosomal copy number changes were observed in clear-cell papillary RCC. No copy number neutral LOH events were detected.

\section{VHL mRNA Expression}

Evaluation of VHL mRNA expression by qRT-PCR was successful in seven clear-cell papillary RCCs. The quality and purity of the RNA extracted from the remaining samples was insufficient for PCR analysis. Expression of VHL mRNA was also assessed in three non-neoplastic kidney samples and five clear-cell RCC samples with 3p25 losses and/or VHL mutations as controls. There was a trend towards higher expression of VHL mRNA in clearcell papillary RCCs (mean Ct value $=1.508 \pm 1.237$ ) when compared with clear-cell RCCs (mean Ct value $=2.970 \pm 2.620$ ) and non-neoplastic kidney samples (mean Ct value $=1.786 \pm 0.228$ ). However, these differences were not statistically different with $P$-values of 0.2677 and 0.7946 , respectively. Furthermore, there was a wide range of expression levels within the tumor subtypes with different samples having widely disparate expression levels (Table 7).

\section{Discussion}

The World Health Organization classification of renal tumors synthesizes morphological, immunohistochemical, molecular, and clinical data to define distinct entities that are biologically and clinically relevant. Over the years, as more data and experience pertaining to neoplasms of the kidney has accumulated, this classification has been refined and expanded to include over 40 tumor types. ${ }^{1}$ Clear-cell RCC, an aggressive and common type, is a 


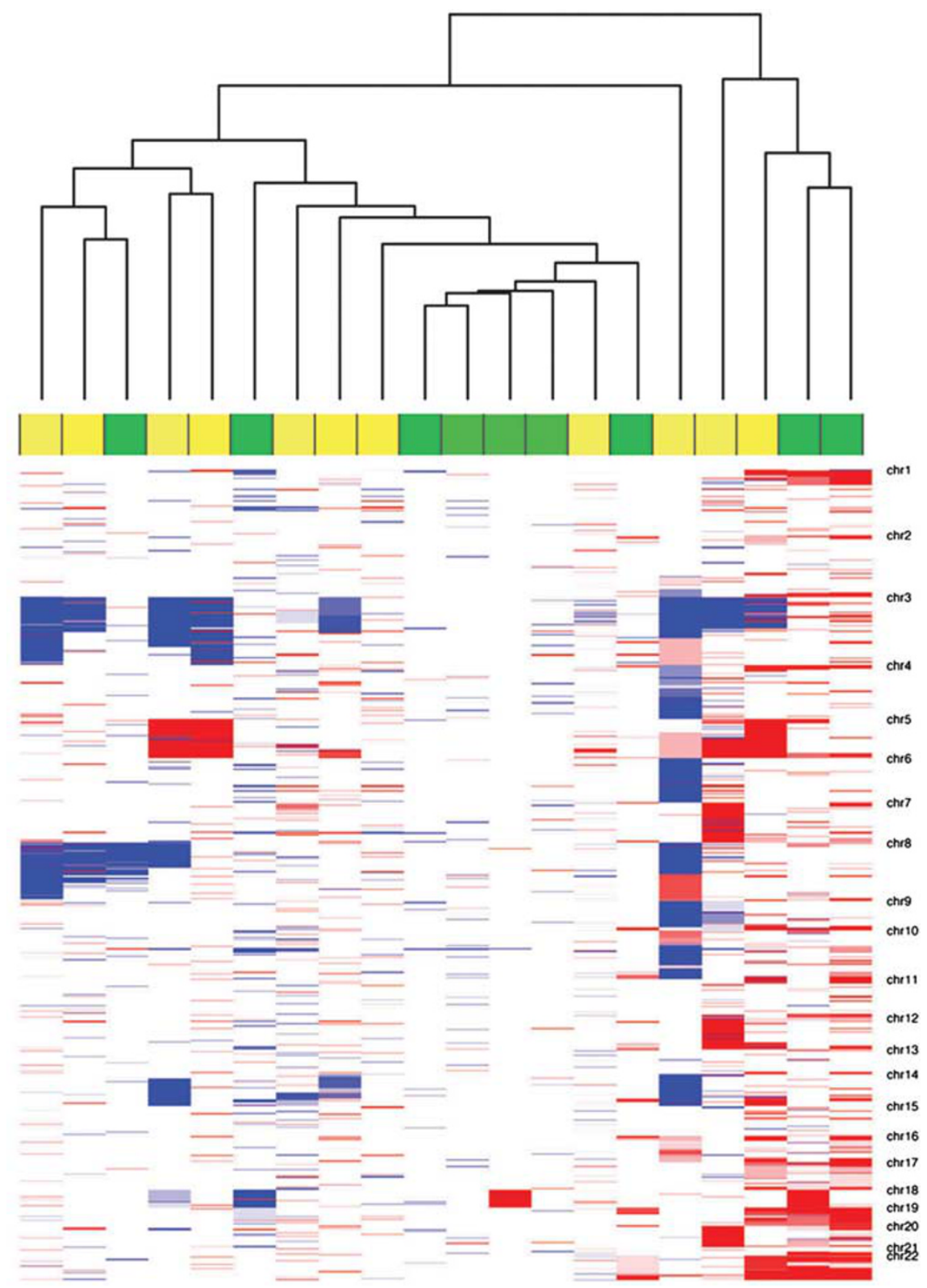

Figure 5 Hierarchical clustering of genome-wide copy number variations from an SNP array does not reveal distinct clustering of clear-cell renal cell carcinoma $(n=11)$ and clear-cell papillary renal cell carcinoma $(n=9)$. The tumor-type designations are indicated above the heatmap, with clear-cell renal cell carcinoma cases represented by yellow boxes and clear-cell papillary renal cell carcinoma cases represented by green boxes. Areas of chromosomal losses are represented by blue and areas of chromosomal gains are represented by red on the heat map. The chromosomes are listed on the right side of the figure in ascending order from top to bottom.

tumor defined by its characteristically clear cytoplasm, distinctive vasculature, expression of CA9 and CD10, alterations of the VHL gene located at chromosome $3 \mathrm{p} 25.3$, and several other recurrent copy number changes such as $5 \mathrm{q}$ gains. ${ }^{1,15,22,23}$ Papillary RCC classically has tubulopapillary architecture, exhibits co-expression of CK7 and AMACR, and harbors trisomies or tetrasomies of chromosomes 7 and $17 .{ }^{1}$ The recently recognized entity clear-cell papillary RCC has consistently been shown to have morphological features intermediate between clear-cell and papillary RCC, as well as an overlapping but unique immunoprofile character-

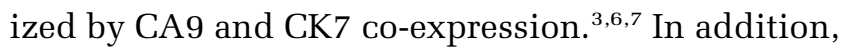
previous studies of clear-cell papillary RCC have failed to show the characteristic cytogenetic findings-namely $3 \mathrm{p}$ losses and trisomies of chromosomes 7 and 17-typically seen in clear-cell and papillary RCC, respectively. ${ }^{3,6}$ Herein, we describe the morphological, immunohistochemical, and molecular features of nine clear-cell papillary RCC cases, with emphasis on the VHL gene and the HIF pathway.

Morphologically, the clear-cell papillary RCCs in our series exhibited diffuse cytoplasmic clarity and various combinations of tubular, papillary, and 
a

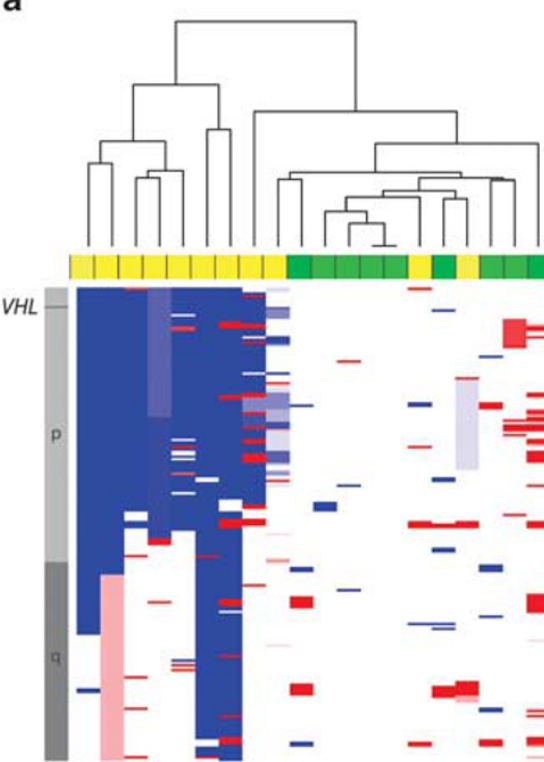

b

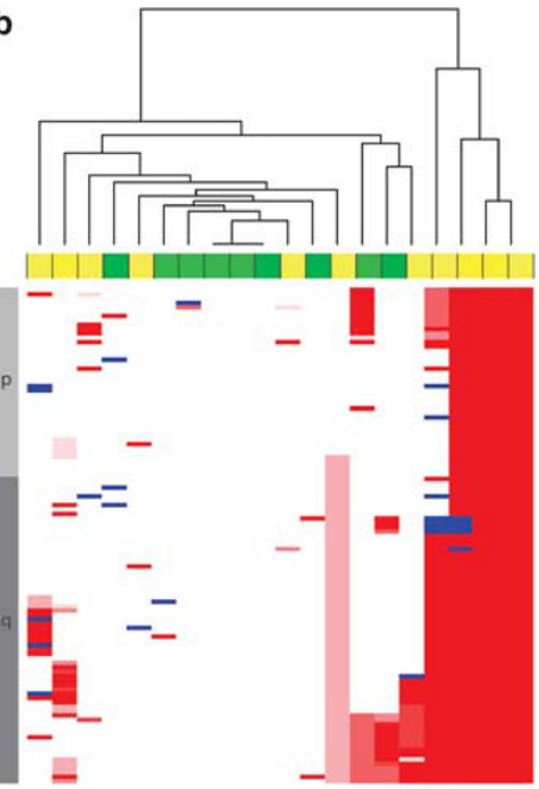

Figure 6 (a) Hierarchical clustering based on copy number changes of chromosome 3 does reveal difference between clear-cell renal cell carcinoma and clear-cell papillary renal cell carcinoma. On the left side of the figure 7 out of 11 (64\%) of the clear-cell renal cell carcinoma cases cluster together as they exhibit loss of a large portion of the short arm of chromosome 3. In contrast, loss of material from the short arm of chromosome 3 was not seen in any of the clear-cell papillary cases evaluated. (b) Hierarchical clustering based on copy number changes of chromosome 5 also reveals difference between clear-cell renal cell carcinoma and clear-cell papillary renal cell carcinoma. On the heatmap, five (45\%) of the clear-cell renal cell carcinoma cases evaluated show amplification of chromosome 5q and cluster together on the right side of the heatmap. None of the clear-cell papillary renal cell carcinoma cases exhibit this copy number change.

Table 6 Significantly different copy number changes

\begin{tabular}{llll}
\hline Aberration & Tumor type with aberration & Minimal overlapping region & Genes in region \\
\hline$-3 \mathrm{p}$ & CRCC $(n=7)$ & 3 pter-3p21.31 & VHL, FHIT, FOXP1, RASSF1A \\
$+5 \mathrm{q}$ & CRCC $(n=5)$ & $5 \mathrm{q} 23.3-5 \mathrm{q}$ ter & CSFR1, ADAMTS2 \\
$-8 \mathrm{p}$ & CRCC $(n=4)$ & $8 \mathrm{p} 22-8 \mathrm{p} 13.2$ & MTUS1
\end{tabular}

CRCC, clear cell renal cell carcinoma.

$P$-value $<0.05$ by $\chi^{2}$ for CRCC vs CCP in all regions listed.

Table 7 Summary of cases of CCP and CRCC with complete VHL and HIF pathway data

\begin{tabular}{|c|c|c|c|c|c|}
\hline Case no. & VHL mutation & $3 p 25$ loss & VHL $m R N A^{\mathrm{a}}$ & $H I F-1 \alpha$ & GLUT-1 \\
\hline CCP1 & - & - & Increased & $90 \%, 3+$ & $90 \%, 3+$ \\
\hline CCP2 & - & - & Decreased & $70 \%, 3+$ & $80 \%, 2+$ \\
\hline CCP3 & - & - & Increased & $80 \%, 3+$ & $80 \%, 3+$ \\
\hline CCP4 & - & - & Increased & $70 \%, 3+$ & $90 \%, 3+$ \\
\hline CCP5 & - & - & Increased & $90 \%, 3+$ & $90 \%, 3+$ \\
\hline CCP8 & - & - & Increased & $95 \%, 3+$ & $90 \%, 3+$ \\
\hline CCP9 & - & - & Decreased & $90 \%, 3+$ & $90 \%, 3+$ \\
\hline CRCC2 & _- & + & Decreased & $90 \% 3+$ & $50 \%, 2+$ \\
\hline CRCC3 & + & + & Unchanged & $80 \%, 3+$ & $70 \%, 3+$ \\
\hline CRCC6 & - & + & Decreased & $95 \%, 3+$ & $50 \%, 3+$ \\
\hline CRCC7 & + & + & Decreased & $90 \%, 3+$ & $95 \%, 3+$ \\
\hline CRCC10 & + & + & Unchanged & $70 \%, 2+$ & $90 \%, 3+$ \\
\hline
\end{tabular}

CRCC, clear cell renal cell carcinoma; CCP, clear cell papillary renal cell carcinoma.

${ }^{\mathrm{a}}$ VHL mRNA expression relative to non-neoplastic kidney samples.

cystic architecture. Areas of acinar growth with the characteristic delicate vasculature typically seen in clear-cell RCC were largely absent in our clear-cell papillary RCC cases. In the single case in which such acinar areas were seen, they were focal and maintained the conspicuous nuclear positioning away from the basement membrane that is typical of clear-cell papillary RCC. In our opinion, this characteristic nuclear positioning is essential for the diagnosis of clear-cell papillary RCC. Despite the 
initial emphasis on papillary architecture in clearcell papillary RCC, this growth pattern is not always prominent, a fact recently highlighted in a large series of these tumors. ${ }^{3}$ When papillary architecture was noted, the fibrovascular cores were typically thin, lined by a single layer of cells with the characteristic nuclear arrangement of clear-cell papillary RCC, and lacked foamy macrophages which are common in papillary RCC. In some areas, the papillations were created by the marked infoldings in tubules and cysts. Cystic change is also common in clear-cell papillary RCC, and in two of our cases this was the predominant growth pattern. These cystic cases raise the possibility of multilocular cystic clear-cell RCC in the differential diagnosis. However, the characteristic nuclear arrangement and at least focal papillary architecture of clear-cell papillary RCC should allow one to separate these two tumor types. We also noted areas of smooth muscle metaplasia in the stroma of four of our tumors. Recently, several groups have described renal tumors with prominent smooth muscle metaplasia and have proposed that such tumors represent a unique entity. ${ }^{2,4}$ We agree with some more recent publications/presentations that tumors designated as 'renal angiomyoadenomatous tumor' or 'RCC with prominent leiomyomatous proliferation' have significant overlap with clear-cell papillary RCC and likely represent morphological variants with particularly exuberant smooth muscle metaplasia. $^{3,7-9}$

In our opinion, based on the characteristic morphological features, clear-cell papillary RCC is easily separable from papillary RCCs with clear-cell changes and clear-cell RCC with focal papillary architecture. ${ }^{3,7,8}$ In only rare instances, the support of immunohistochemical staining may be an absolute requirement for making this distinction. ${ }^{31}$

The unique co-expression of CK7 and CA9 seen in clear-cell papillary RCC in previous studies was confirmed in our series. ${ }^{3,6-8}$ All of our cases strongly expressed these markers. None of our clear-cell papillary RCCs expressed CD10 or AMACR makers that were expressed by the majority of clear-cell RCC and papillary RCC, respectively. We also evaluated the expression of the high molecular weight CK$34 \beta$ E12-which labeled over half of the clear-cell papillary RCCs (56\%), but none of the clear-cell or papillary RCCs. Thus, based on these results the immunoprofile of clear-cell papillary RCC can be summarized as $\mathrm{CK} 7+$, CA9+, 34 $\beta \mathrm{E} 12 \pm$, CD10-, and AMACR-.

Of interest, one clear-cell RCC case included in this study exhibited patchy labeling for CK7. We classified this case as a clear-cell RCC based on the absence of the morphological criteria characteristics of clear-cell papillary RCC described in the Materials and methods section. Although the immunostained TMA slide showed strong co-expression of CK7 and CA9 in this case, immunostains performed on whole tumor sections revealed patchy CK7 staining primarily in and around areas of cystic growth. The expression of CK7 in clear-cell RCCespecially small tumors-has been documented in the literature. ${ }^{5}$ We have seen CK7 staining in clearcell RCC cases in which the morphological diagnosis of clear-cell papillary RCC was not even entertained owing to the absence of characteristic H\&E features, and in those cases the CK7 labeling was patchy. Thus, we believe that this case represents an uncommon clear-cell RCC with patchy CK7 staining. Therefore, in addition to the architectural pattern, cytoplasmic clarity, and characteristic nuclear morphology, diffuse, strong co-expression of CA9 and CK7 can be used as supporting evidence for classification of a renal tumor as clear-cell papillary RCC.

Loss of function of the VHL gene ultimately leads to overexpression of a variety of proteins that are targets of the HIF pathway. ${ }^{18-20}$ CA9 is one of the better-known HIF targets and has been shown to be useful as an immunohistochemical marker of clearcell RCC. ${ }^{32,33}$ As noted above in our series as well as in previous studies, clear-cell papillary RCC also strongly expresses CA9. However, the pattern of expression of CA9 in clear-cell papillary RCC differs from that seen in clear-cell RCC in that most cells in clear-cell papillary RCC lack labeling on the luminal aspect. This pattern of staining was not observed in any of the clear-cell RCCs evaluated in this study. Two additional markers of HIF pathway activationGLUT-1 and HIF- $1 \alpha$-were also overexpressed at the protein level in the clear-cell papillary RCC evaluated in this study. Overexpression of these markers was not seen in cases of papillary RCC, whereas strong expression of both markers was seen in clearcell RCC. GLUT-1 was diffusely and strongly positive in all of the clear-cell papillary RCC cases, as well as in all of the clear-cell RCC cases studied. Similarly, HIF-1 $\alpha$ overexpression was seen in $100 \%$ of clear-cell papillary and 91\% of clear-cell RCC cases. Although numerous genetic, epigenetic, and physiologic factors can result in overexpression of these proteins, given the known prominent role of $V H L$ inactivation in clear-cell RCC, this would be one possible explanation.

To investigate the possibility that alterations of the VHL gene have a role in overexpression of HIFrelated markers and tumorigenesis in clear-cell papillary RCC, we performed mutational analysis of the VHL gene, evaluated the tumors for loss of heterozygosity of the short arm of chromosome 3 , and examined the expression of VHL mRNA in our clear-cell papillary RCC cases and clear-cell RCC controls. Silencing of the $V H L$ gene via mutations is common in sporadic clear-cell RCC having been documented in $37-80 \%$ of cases depending on the methods used. ${ }^{17}$ In our series, none of the clear-cell papillary RCC cases harbored VHL mutations, whereas four mutations of the VHL gene were seen in three clear-cell RCCs $(27 \%)$. Sequencing of matched normal kidney samples confirmed that 
these mutations were somatic and only changes that would result in an amino-acid change were counted as mutations in this study. All of the mutations seen in our clear cell RCC have been described previously in the literature and are predicted to result in a nonfunctional/dysfunctional VHL protein product. $^{17}$ The low incidence of VHL mutations seen in clearcell RCC may in part reflect the sample size or the sequencing methods used.

SNP arrays are a relatively new Chip-based method that allow for evaluation of genome-wide copy number changes. Several studies utilizing this technology to study and classify renal tumors have been performed and the results indicate that this is an accurate method for separating renal tumor subtypes based on previously known chromosomal aberrations. ${ }^{34,35}$ Using SNP arrays to study clear-cell RCC specifically has resulted in the detection of $3 p$ losses in $91-100 \%$ of cases and $5 q$ gains in $40-45 \%$ of cases. ${ }^{24,34,35}$ In comparison, previous conventional cytogenetic, FISH, and comparative genomic hybridization studies have detected these abnormalities less frequently. For example, recent studies of clearcell RCC using these methodologies have had a rate of $3 p$ loss detection ranging from 60 to $76 \%$ of the cases evaluated. ${ }^{22,23}$

In our series, $3 p$ losses-including the region of the VHL gene-and $5 q$ gains were the most frequent chromosomal copy number change detected in clear-cell RCC. Losses of $3 p$ were seen in $7 / 11$ (64\%) of clear-cell RCCs, whereas $5 \mathrm{q}$ gains were observed in $5 / 11(45 \%)$. Losses of $8 p$ were also detected in 4/11 clear-cell RCC cases (36\%) and, like $3 p$ losses and $5 q$ gains, were not seen in any of the clear-cell papillary RCC cases. The difference in frequency of $3 p$ losses and $5 q$ gains between the two groups was statistically significant with $P$-values of 0.006 and 0.025 , respectively. We did not detect trisomies or tetrasomies of chromosomes 7 or 17 in any of the cases evaluated. This finding was confirmed in all of our clear-cell papillary RCCs by interphase fluorescence in situ hybridization using centromeric probes for chromosomes 7 and 17 (data not shown).

Our qRT-PCR studies revealed relative overexpression of VHL mRNA in clear-cell papillary RCC compared with non-neoplastic renal parenchyma and clear-cell RCC cases harboring $3 p$ losses and/or VHL mutations. This finding supports the notion that the molecular mechanism underlying clear-cell papillary RCC may be distinct from clear-cell RCC and not related to abrogation of VHL signaling. However, it should be noted that there was a wide range of expression levels of VHL mRNA in clearcell papillary RCC, with some cases having very low expression levels (Table 7). The finding of decreased expression of $V H L$ mRNA in two of five clear-cell papillary RCC cases evaluated requires further explanation if the absence of $V H L$ gene alterations is to be used as evidence that these tumors are not simply variants of clear-cell RCC. Although we did exclude the two most common mechanisms of VHL silencing in these two clear-cell papillary RCC cases-namely VHL mutation and chromosome 3p25 losses-we did not rule out all the possible mechanisms of $V H L$ silencing. In particular, we did not evaluate the possibility of VHL promoter hypermethylation-an epigenetic change known to lead to VHL silencing and decreased VHL mRNA expression in clear-cell RCC. ${ }^{16}$ We also did not investigate the possibility of microRNA (miRNA)induced VHL silencing that could explain the decreased mRNA levels in these two cases. ${ }^{36}$ Although previous studies of clear-cell papillary RCC did not evaluate VHL mRNA or miRNA expression patterns, one study did evaluate VHL promoter hypermethylation in 2 of 36 cases and both of these cases were found to have a normal methylation status. ${ }^{3}$ We also noted variable expression of VHL mRNA in the clear-cell RCC included in our study with two cases showing expression levels comparable to non-neoplastic renal tissue. Both of these cases had documented VHL mutations, which would alter VHL protein function, but not necessarily VHL mRNA expression and, thus, activation of the HIF pathway in these cases would be expected (Table 7).

Overall, our results support the findings of previous studies that clear-cell papillary RCC have unique morphological and immunohistochemical findings-in particular strong, diffuse co-expression of CA9 and CK7. These tumors, when strictly defined, do not harbor mutations of the VHL gene or the characteristic chromosomal changes seen in clear-cell or papillary RCC. Interestingly, these tumors do overexpress markers of HIF pathway activation-CA9, GLUT-1, and HIF-1 $\alpha$-but appear to have normal or even elevated VHL mRNA expression relative to non-neoplastic controls. Although we cannot completely explain these findings in clearcell papillary RCC, a wide range of genetic, epigenetic and physiologic factors could be the cause. We did not exclude mutations of several genes known to predispose individuals to renal tumors that also lead to HIF overexpression-such as fumarate hydratase and succinate dehydratase $\mathrm{B}$ mutations. ${ }^{37}$ Future studies examining the possible role of such genes would be of great interest as none of the studies to date have not shown any specific molecular alteration associated with clear-cell papillary RCC.

To conclude, currently the definition of clear-cell papillary RCC rests on unique morphological and immunohistochemical features in conjunction with the absence of molecular findings characteristic of other renal tumors rather than that on the presence of any tumor-type- specific genetic alterations. Despite the absence of a molecular marker in clearcell papillary RCC, the bulk of the data suggest that it represents a unique entity. Future studies aimed at explaining the overexpression of HIF-related markers in these tumors may elucidate the molecular mechanisms by which these neoplasms arise. 


\section{Acknowledgements}

We acknowledge Agnes Viale in the Genomics Core facility at the Sloan-Kettering Institute for her technical assistance with the qRT-PCR and the SNP array. The Genomics core is supported by NCI Grant No. P30-CA008748. We thank Adriana Heguy and Igor Dogalev in the Translational Core Facility at the Sloan-Kettering Institute for their assistance with the sequencing and mutational analysis. This work was supported, in part, by a 2008 Scholars Grant (SMR) from the College of American Pathologist Foundation.

\section{Disclosure/conflict of interest}

The authors declare no conflict of interest.

\section{References}

1 Eble JN, Sauter G, Epstein JI, et al (eds). Tumours of the kidney In: World Health Organization Classification of Tumours: Pathology and Genetics, Tumours of the Urinary System and Male Genital Organs. IARC Press: France, 2004, pp 9-43.

2 Michal M, Hes O, Nemcova J, et al. Renal angiomyoadenomatous tumor: morphologic, immunohistochemical, and molecular genetic study of a distinct entity. Virchows Arch 2009;454:89-99.

3 Aydin H, Chen L, Cheng L, et al. Clear cell tubulopapillary renal cell carcinoma: a study of 36 distinctive low-grade epithelial tumors of the kidney. Am J Surg Pathol 2010;34:1608-1621.

4 Brunelli M, Menestrina F, Segala D, et al. Renal cell carcinoma with prominent leiomyomatous proliferation appears not to be a variant of clear cell renal cell carcinoma. Mod Pathol 2009;22:160A.

5 Mai KT, Kohler DM, Belanger EC, et al. Sporadic clear cell renal cell carcinoma with diffuse cytokeratin 7 immunoreactivity. Pathology 2008;40:481-486.

6 Gobbo S, Eble JN, Grignon DJ, et al. Clear cell papillary renal cell carcinoma: a distinct histopathologic and molecular genetic entity. Am J Surg Pathol 2008;32: 1239-1245.

7 Tickoo SK, Reuter VE. Clear cell papillary renal cell carcinoma. In: Amin MB, McKenney JK, Tickoo SK, Paner GP, Shen SS, Velazquez EF, Cubilla EL, Ro JY, Reuter VE (eds). Diagnostic Pathology: Genitourinary. Amirsys Publishing Inc, 2010, pp 1-106-1-111.

8 Tickoo SK, Reuter VE. Differential diagnosis of renal tumors with papillary architecture. Adv Anat Pathol 2011;18:120-131.

9 Behdad A, Monzon FA, Hes O, et al. Relationship between sporadic clear cell-papillary renal cell carcinoma (CP-RCC) and renal angiomyoadenomatous tumor (RAT) of the kidney: analysis by virtualkaryotyping, fluorescent in situ analysis and immunohistochemistry (IHC). Mod Pathol 2011;24(Suppl):179A.

10 Herrera LP, Hes O, Hirsch M, et al. Clear cell-papillary renal cell carcinoma (cp-rcc) not associated with end stage renal disease: clinicopathologic analysis of 50 tumors confirming a novel subtype of renal cell carcinoma (rcc) occurring in a sporadic setting. Mod Pathol 2011;24(Suppl):197A.
11 Tickoo SK, dePeralta-Venturina MN, Harik LR, et al. Spectrum of epithelial neoplasms in end-stage renal disease with emphasis on histologic patterns distinct from those in sporadic adult renal neoplasms. Am J Surg Pathol 2006;30:141-153.

12 Duan L, Youssef RF, Margulis V, et al. Clear cell papillary renal cell carcinoma: clinicopathologic, immunohistochemical, and molecular analysis. Mod Pathol 2011;24(Suppl):189A.

13 Williamson SR, Eble JN, Cheng L, et al. The spectrum of morphologic findings in clear cell papillary renal cell carcinoma. Mod Pathol 2011;24(Suppl):230A.

14 Cohen HT, McGovern FJ. Renal-cell carcinoma. N Engl J Med 2005;353:2477-2490.

15 Kovacs G, Erlandsson R, Boldog F, et al. Consistent chromosome $3 p$ deletion and loss of heterozygosity in renal cell carcinoma. Proc Natl Acad Sci USA 1988; 85:1571-1575.

16 Arai E, Ushijima S, Tsuda H, et al. Genetic clustering of clear cell renal cell carcinoma based on array-comparative genomic hybridization: its association with DNA methylation alteration and patient outcome. Clin Cancer Res 2008;14:5531-5539.

17 Nickerson ML, Jaeger E, Shi Y, et al. Improved identification of von Hippel-Lindau gene alterations in clear cell renal tumors. Clin Cancer Res 2008;14: 4726-4734.

18 Kim WY, Kaelin WG. Role of VHL gene mutation in human cancer. J Clin Oncol 2004;22:4991-5004.

19 Krieg $\mathrm{M}$, Haas $\mathrm{R}$, Brauch $\mathrm{H}$, et al. Up-regulation of hypoxia-inducible factors HIF- $1 \alpha$ and HIF-2 $\alpha$ under normoxic conditions in renal carcinoma cells by von Hippel-Lindau tumor suppressor gene loss of function. Oncogene 2000;19:5435-5443.

20 Wiesener MS, Münchenhagen PM, Berger I, et al. Constitutive activation of hypoxia-inducible genes related to overexpression of hypoxia-inducible factor$1 \alpha$ in clear cell renal carcinomas. Cancer Res 2001;61: 5215-5222.

21 Grabmaier K, de Weijert MCA, Verhaeg GW, et al. Strict regulation of CAIXG ${ }^{250 / M N}$ by HIF- $1 \alpha$ in clear cell renal cell carcinoma. Oncogene 2004;23:5624-5631.

22 Gayrard N, Cacheux V, Iborra F, et al. Cytogenetic studies of 24 renal epithelial tumors with von HippelLindau and fragile histidine triad protein expression correlation. Arch Pathol Lab Med 2008;132:965-973.

23 Klatte T, Rao PN, de Martino M, et al. Cytogenetic profile predicts prognosis of patients with clear cell renal cell carcinoma. J Clin Oncol 2009;27: $746-753$.

24 Toma MI, Grosser M, Herr A, et al. Loss of heterozygosity and copy number abnormality in clear cell renal cell carcinoma discovered by high-density Affymetrix $10 \mathrm{~K}$ single nucleotide polymorphism mapping array. Neoplasia 2008;10:634-642.

25 Veeriah S, Brennan C, Meng S, et al. The tyrosine phosphatase PTPRD is a tumor suppressor that is frequently inactivated and mutated in glioblastoma and other human cancers. Proc Natl Acad Sci USA 2009;106:9435-9440.

26 Rozen S, Skaletsky HJ. Primer3 on the WWW for general users and for biologist programmers In: Krawetz S, Misener S (eds). Bioinformatics Methods and Protocols: Methods in Molecular Biology. Humana Press: Totowa, NJ, 2000, pp 365-386.

27 Andrews J, Kennette W, Pilon J, et al. Multi-platform whole-genome microarray analyses refine the epige- 
netic signature of breast cancer with gene expression and copy number. PLos One 2010;5:e8665.

28 Bengtsson H, Wirapati P, Speed TP. A Single array preprocessing method for estimating full-resolution raw copy numbers from all Affymetrix genotyping arrays including genomewide SNP 5\&6. Bioinformatics 2009;25:2149-2156.

29 Olshen AB, Venkatraman ES, Lucito R, et al. Circular binary segmentation for the analysis of array-based DNA copy number data. Biostatistics 2004; 5:557-572.

30 Taylor BS, Barretina J, Socci ND, et al. Functional copy number alterations in cancer. PLoS One 2008; 3:e3179.

31 Gobbo S, Eble JN, Maclennan GT, et al. Renal cell carcinomas with papillary architecture and clear cell components: the utility of immunohistochemical and cytogenetical analyses in differential diagnosis. Am J Surg Pathol 2008;32:1780-1786.

32 Liao SY, Brewer C, Zavada J, et al. Identification of the MN/CA9 antigen as a diagnostic biomarker of clear cell carcinoma of the kidney. Cancer Res 1997;57: 2827-2831.
33 Al-Ahmadie HA, Alden D, Qin L-X, et al. Carbonic anhydrase IX expression in clear cell renal cell carcinoma: an immunohistochemical study comparing 2 antibodies. Am J Surg Pathol 2008;32:377-382.

34 Kim HJ, Shen SS, Ayala AG, et al. Virtual-karyotyping with SNP microarrays in morphologically challenging renal cell neoplasms: a practical and useful diagnostic modality. Am J Surg Pathol 2009;33:1276-1286.

35 Monzon FA, Hagenkord JM, Lyons-Weiler MA, et al. Whole genome SNP arrays as a potential diagnostic tool for the detection of characteristic chromosomal aberrations in renal epithelial tumors. Mod Pathol 2008;21:599-608.

36 Lal A, Navarro F, Maher C, et al. miR-24 inhibits cell proliferation by suppressing expression of E2F2, MYC and other cell cycle regulator genes by binding to 'seedless' 3'UTR microRNA recognition elements. Mol Cell 2009;35:610-625.

37 Pollard PJ, Briere JJ, Alam NA, et al. Accumulation of Krebs cycle intermediates and over-expression of HIF1- $\alpha$ in tumours which result from germline $\mathrm{FH}$ and SDH mutations. Hum Mol Genet 2005;14: 2231-2239. 